Colombia Médica

Letter to Editor

\section{Parallel analysis and MBI-HSS: How many factors?}

History: Received 21 October 2013; Revised 25 November 2013; Accepted 9 December 2013

Mr. Editor: It has been only recently possible to validate the Maslach Burnout Inventory-Human Services Survey (MBI-HSS) ${ }^{1}$ among health professionals of $\mathrm{Cali}^{2}$, an important step for using this instrument with local empirical support in regard to its reliability of scoring and internal structure. However, two aspects of this analysis can be considered as methodological weaknesses. First, the Cronbach alpha coefficient was calculated for the total group of items, and this is absolutely inappropriate because: a)the authors did not demonstrate empirical support for accomplishing this (e.g., a hierarchical factor analysis), b) the literature indicates that factors in the MBI-HSS are generally independent, a characteristic also reported by Córdoba et al. ${ }^{2}$, and the same authors of the MBI-HSS ${ }^{1}$ ) the authors did not report the inter-factor correlations with which an appreciation could have been obtained, at least an heuristic one of the common degree of variance among the factors. Secondly, the authors obtained seven factors in their exploratory factor analysis; this large number of actors seems to be a product of applying a factor retention method that is now consensually seen as inaccurate and little recommended ${ }^{3,4}$ Specifically, it is known as Kaiser's rule, Guttman's rule or simply K1. The problem identified with this method is its over-estimation of the number of factors to be retained ${ }^{3,4}$, a situation that clearly occurs in the results reported by Cordoba et $a l_{.}^{2}$, as reported in their Table 2.

A more accurate method which has gained a scientific consensus for good practices for retaining the number of factors is called parallel analysis ${ }^{3,4}$. This procedure is based on the work of Horn ${ }^{4}$, which consists of randomly creating the same number of variables as the number of items analyzed (in the case of MBI-HSS, 22 items),correlating them and extracting eigenvalues against which the eigenvalues derived from the empirical data under analysis are compared. This procedure was applied to the eigenvalues reported by Cordoba et al. ${ }^{2}$, in Table 2 by means of the Monte Carlo PCA ${ }^{5}$ program (100 replications). Our results are shown in Table 1.

The appropriate number of factors to retain is achieved by making a one to one comparisons of the eigenvalues, keeping the empirical eigenvalue that is less than the random eigenvalue. Conceptually, this indicates that the significant eigenvalues must be greater than those generated randomly. In Table 1, the number of eigenvalues to retain is 3 , which is exactly the same number of factors underlying the MBI-HSS. Validating the result with a conceptual analysis of these three factors, would leave one to conclude that the factorial structure of the MBI-HSS is replicable in the sample studied. Compared with the first result of the authors (7 factors), the methodological difference is clear. Finally, we note that the use of parallel analysis should be recommended for making more accurate decisions about the number of factors to retain.
Table 1. The eigenvalues of Cordoba et al and those generated randomly (100 replications)

\begin{tabular}{lcc}
\hline No. of eigen values & Córdoba et al. & Random \\
\hline 1 & 4.17 & 1.51 \\
2 & 2.06 & 1.42 \\
3 & 1.45 & 1.35 \\
4 & 1.23 & 1.29 \\
5 & 1.15 & 1.25 \\
6 & 1.07 & 1.2 \\
7 & 1.05 & 1.16 \\
8 & - & 1.11 \\
9 & - & 1.07 \\
10 & - & 1.03 \\
11 & - & 1 \\
12 & - & 0.96 \\
13 & - & 0.93 \\
14 & - & 0.89 \\
15 & - & 0.85 \\
16 & - & 0.82 \\
17 & - & 0.79 \\
18 & - & 0.75 \\
19 & - & 0.72 \\
20 & - & 0.68 \\
21 & - & 0.64 \\
22 & -59 \\
\hline
\end{tabular}

Conflict of interest

None declared

\section{References}

1. Maslach C, Jackson, S. Maslach Burnout Inventory-Human Services Survey (MBI-HSS). In: Maslach C, Jackson, S. Leiter M. editors. Maslach Burnout inventory manual. Mountain View: Consulting Pschologists Press; 1996.

2. Córdoba L, Tamayo J, González M, Martinez M, Rosales A, Barbato S. Adaptation and validation of the Maslach Burnout inventory-human services survey in Cali, Colombia. Colomb Med. 2011; 42(3): 286-93.

3. Hayton JC, Allen DG, Scarpello V. Factor retention decisions in exploratory factor analysis: A tutorial on parallel analysis. Organ Res Meth. 2004; 7(2): 191-205.

4. Dinno A. Exploring the sensitivity of Horn's parallel analysis to the distributional form of random data. Multivariate Behav Res. 2009; 44(3): $362-88$.

5.Watkins MW. Monte Carlo PCA for parallel analysis [computer software]. State College, PA: Ed \& Psych Associates. 2000. 


\section{Responding to: Parallel analysis and MBI-HSS}

Regarding the article, entitled "Adaptation and validation of the Maslach Burnout Inventory-Human Services Survey in Cali, Colombia" as published in Colombia Médica, please note the following clarifications:

Cronbach's Alpha Coefficient for the total MBI scale can be considered inappropriate in the usage and evaluation of the MBI given the independence of the factors for the MBI-HSS; however, we, the authors do not share this statement as this result does not affect the conclusions of the study. .

An exploratory factor analysis was used mainly as a method to cross-validate the item analysis previously conducted ${ }^{1}$ and, secondarily, to examine the structure of relationships between variables, to detect possible multi-dimensionality of the construct assessed, and to explore the validity of the construct for the MBIHSS so that the underlying dimensions of the items in the context could be identified ${ }^{2}$. From this analysis, the researchers wanted to explore the internal structure and dimensionality proposed in the theoretical model for the MBI-HSS from the data collected without making assumptions about the same model with three dimensions evaluated in the context; as the title suggests, its purpose was exploratory in nature ${ }^{1-3}$. However, later the confirmatory factor analysis was used in order to statistically contrast the hypothesis based on the grouping of the items proposed by the theory or model suggested by the MBI-HSS authors. This analysis allowed the researchers to test the hypothesis by inferential techniques and provide informative analytical options ${ }^{4}$. Currently, it is recommended that before proceeding with the application of a confirmatory factor analysis that exploratory factor analysis procedures are used ${ }^{1}$, as was previously mentioned.

For the exploratory factor analysis, Kaiser's criterion was used as a factor retention method, although today it is not the method most recommended ${ }^{6-8}$; in numerous articles it has been used as a tool to obtain a first approximation of the factorial structure of the MBI-HSS ${ }^{9-11}$. As the more variables in the analysis the less the variance needed to explain a factor, so the Kaiser criterion tends to suggest too many factors ${ }^{7}$. Therefore, some suggest that it be used with other indicators ${ }^{12}$ or that a confirmatory factor analysis is conducted to validate the number of factors ${ }^{5}$. Currently, parallel analysis is widely accepted to determine the number of factors to be retained ${ }^{5.7}$.

Similarly, although the exploratory factor analysis has provided a seven-factor structure, studies that have evaluated the psychometric properties of the MBI with other populations show a greater number of factors than the original version ${ }^{13-15}$ by this same method.

Referencing the application of parallel analysis in the retention of the number of factors in the exploratory factor analysis (Fig. 1), it clearly shows that the results are consistent with the confirmatory factor analysis and show strong evidence in support of the three-factor structure of the original model (values greater than simulated Eigenvalues and those from re-sampling). It must be noted that the confirmatory model allows evaluation of the statistical fit between the original MBI model and our data, and
Figure 1. Eigen values and parallel analysis over 1000 replications using the $\mathrm{R}\left({ }^{17}\right)$ statistical software

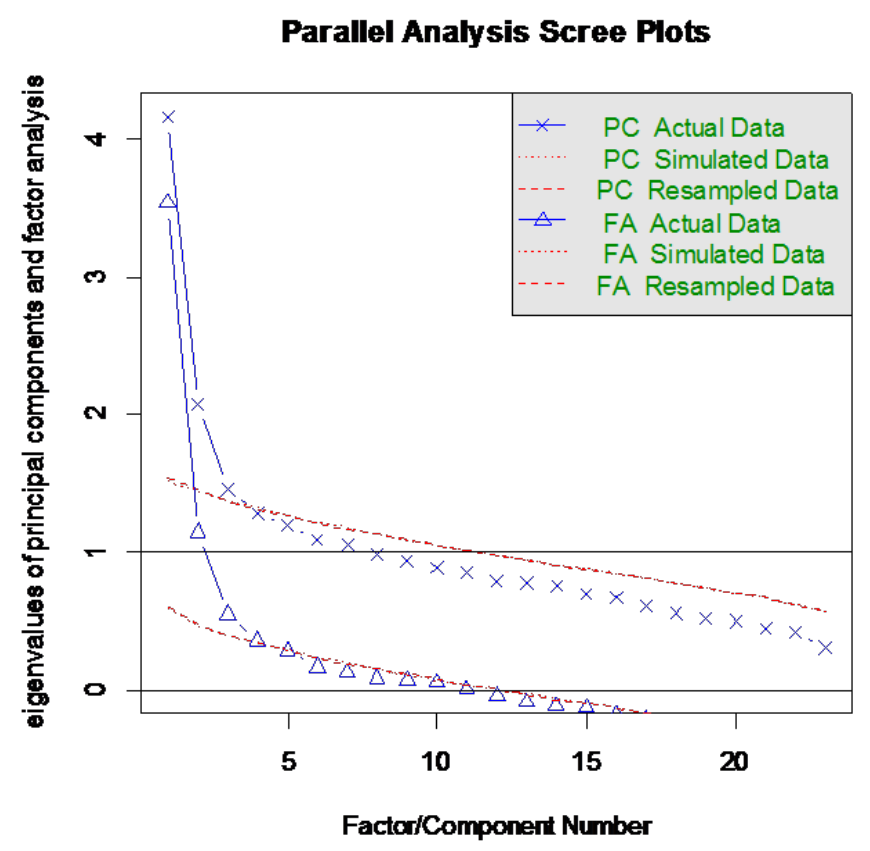

the exploratory factor analysis can in no way be used as this model incorporates few substantive assumptions and allows for each item to depend on all common factors so that the interpretation is heuristic and difficult ${ }^{16}$. Therefore, the confirmatory factor analysis model corrects the inherent deficiencies in the exploratory perspective and leads to greater support for the hypothesis of the original structural model of the MBI-HSS.

We emphasize that through the proposed analysis one does not reject the hypothesis of a three-factor structure for evaluating Burnout syndrome in the population studied. Finally, it is appropriate to note that the researchers did not make any decision on the dimensionality of MBI-HSS through the exploratory factor analysis, but rather used the confirmatory factor analysis to decide on the factorial structure of the MBI. This analysis was done for a factorial structure of seven, six, five, four and two; however, these data were not published because a good fit of the structural equation model to a factor structure as previously found.

\section{References}

1. Floyd, FJ, Widaman KF. Factor analysis in the development and refinement of clinical assessment instruments. Psychological Assessment. 1995; 7: 286-99.

2. Hwan S, Lee M. Examining the psychometric properties of the Maslach Burnout Inventory with a sample of child protective service workers in Korea. Children Youth Serv Rev. 2009; 31: 20610 .

3. Henson RK, Roberts JK. Use of Exploratory Factor Analysis in Published Research:Common Errors and Some Comment on Improved Practice. Educat Psycholog Measurem. 2006; 66: 3. 
4. Thompson B. Exploratory and confirmatory factor analysis: understanding conceptsand applications. Washington, DC: American Psychological Association. 2004.

5. Costello AB, Osborne JW. Best practices in exploratory factor analysis: four recommendations for getting the most from your analysis. Practical Assessm Res Evaluat. 2005; 10(7): 173-8.

6. Patil V, Singh S, Mishra S, Donavan T. Efficient theory development and factor retention criteria: Abandon the eigenvalue greater than one' criterion. J Busin Res. 2008; 61: 162-70.

7. Hayton J, Allen D, Scarpello V. Factor retention decisions in exploratory factor analysis: A tutorial on Parallel Analysis. Organiz Res Methods. 2004; 7(2): 191-205.

8. Williams B, Brown T, Onsman A. Exploratory factor analysis: A five-step guide for novices. J Emerg Prim Health Care. 2010; 8(3): article 990399.

9. Galanakis M, Moraitou M, Garivaldis F, Stalikas A. Factorial Structure and Psychometric Properties of the Maslach Burnout Inventory (MBI) in Greek Midwives. Eur J Psychol. 2009; 4: 52-70.

10. Mojsa J, Dylag A, Palczynska E. Psychometric properties of a Polish version of the Maslach Burnout Inventory General Survey (MBI-GS) in a group of Information and Communication Technology(ICT) specialists. Ergonomia IJE\&HF. 2006; 28(4): 351-61.
11. Millán A, DAuberterre M. Propiedades psicométricas del Maslach Burnout Inventory-GS en una muestra multiocupacional venezolana. Rev Psicología. 2012; 30(1): 103-28.

12. Nunnally J, Bernstein I. Teoría psicométrica. México: McGraw-Hill. 1995.

13. Olivares V. Analysis of psychometric properties of the Maslach Burnout inventory human services (MBI-HSS) in Chilean professionals. Cienc Trab. 2009; 11(34): 217-21.

14. Chao SF, McCallion PP, Nickle TT. Factorial validity and consistency of the Maslach Burnout Inventory among staff working with persons with intellectual disability and dementia. J Intell Disab Res. 2011; 55(5): 529-36.

15. Gil-Monte P. Validez factorial de la adaptación al español del Maslach Burnout inventory-general survey. Salud Publica Mex. 2002; 44: $33-40$

16. Batista J, Coenders G, Alonso J. Análisis factorial confirmatorio. Su utilidad en la validación de cuestionarios relacionados con la salud. Med Clin. 2004; 122(Supl 1): 21-7.

17. R Core Team. R: A language and environment for statistical computing. R Foundation for Statistical Computing, Vienna, Austria. Accessed: 1 December 2013. Available from: http:// www.r-project.org/. 